$$
\text { CONF- } 961202--5
$$

[Paper submitted for the MRS 1996 Fall Meeting, held in Boston, Mass., Dec. 2-6, 1966. Symposium II: Scientific Basis for Nuclear Waste]

FUNDAMENTAL CHEMISTRY AND MATERIALS SCIENCE OF AMERICIUM IN SELECTED IMMOBILIZATION GLASSES *

R. G. Haire ${ }^{1}$ and Nathan A. Stump ${ }^{2}$,

'Oak Ridge National Laboratory, Chemical and Analytical Sciences Division, P. O. Box 2008, MS 6375, Oak Ridge, TN 37831-6375

${ }^{2}$ Dept. of Physical Science, Winston-Salem State University, 601 Martin Luther King, Jr. Drive, Winston-Salem, NC 27110
RECEIVED

NOV 191996

OSTI

\footnotetext{
"The submitted manuscript has been authored by a contractor of the U.S. Government under contract No. DE-AC05-96OR22464.

Accordingly, the U.S. Government retains a

nonexclusive, royalty-free license to publish or

reproduce the published form of this

contribution, or allow others to do so, for US.

Government purposes".
}

[*Research sponsored by the Division of Chemical Sciences, Office of Basic Energy Sciences, US Dept. of Energy, under contract DE-ACO5-96OR22464 with Oak Ridge National Laboratory, managed by Lockheed Martin Energy Research Corp.] 
DISCLAIMER

This report was prepared as an account of work sponsored by an agency of the United States Government. Neither the United States Government nor any agency thereof, nor any of their employees, makes any warranty, express or implied, or assumes any legal liability or responsibility for the accuracy, completeness, or usefulness of any information, apparatus, product, or process disclosed, or represents that its use would not infringe privately owned rights. Reference herein to any specific commercial product, process, or service by trade name, trademark, manufacturer, or otherwise does not necessarily constitute or imply its endorsement, recommendation, or favoring by the United States Government or any agency thereof. The views and opinions of authors expressed herein do not necessarily state or reflect those of the United States Government or any agency thereof. 


\section{DISCLAMMER}

Portions of this document may be illegible in electronic image products. Images are produced from the best available original document. 


\title{
FUNDAMENTAL CHEMISTRY AND MATERIALS SCIENCE OF AMERICIUM IN SELECTED IMMOBILIZATION GLASSES
}

\author{
R. G. HAIRE *, N. A. Stump ** \\ *Oak Ridge National Laboratory, P. O. Box 2008, Oak Ridge, TN 37831-6375, rgh@ornl.gov \\ **Dept. Physical Sciences, Winston-Salem State University, 601 Martin Luther King, Jr. Dr., \\ Winston-Salem, NC 27110
}

\section{ABSTRACT}

We have pursued some of the fundamental chemistry and materials science of americium in three glass matrices, two being high-temperature $\left(850^{\circ}\right.$ and $1400^{\circ} \mathrm{C}$ melting points) silicate-based glasses and the third a sol-gel glass. Optical spectroscopy was the principal investigating tool in the studies. One aspect of this work was to determine the oxidation state exhibited by americium in these matrices, as well as factors that control and/or may alter this state. We have noted a correlation between the oxidation state of the f-elements in the two high-temperature glasses with their high-temperature oxide chemistries. One exception was americium: although americium dioxide is the stable oxide encountered in air, when this dioxide was incorporated into the high-temperature glasses, only trivalent americium was found in the products. When trivalent americium was used to prepare the sol-gel glasses at ambient temperature, and after these products were heated in air to $800^{\circ} \mathrm{C}$, only trivalent americium was observed. Potential explanations for the unexpected behavior of americium is offered in the context of its basic chemistry. Experimental spectra, spectroscopic assignments and other pertinent data obtained in the studies are discussed.

\section{INTRODUCTION}

The science of immobilization materials for nuclear waste has been an active topic for decades and many studies on this subject have been performed and reported. These have ranged from examining physical properties of the host materials to generating modeling approaches for projecting the performance of materials. The latter depend heavily on valid, fundamental information about the materials. One of our objectives has been to generate information about the fundamental chemistry and materials science of $4 \mathrm{f}$ - and $5 \mathrm{f}$-elements in three selected glass matrices. These have included two high-temperature $\left(850^{\circ}\right.$ and $1400^{\circ}$ melting points), silicatebased glasses and glasses prepared via an aqueous sol-gel route. Optical spectroscopy (absorption, fluorescence, Raman) was the principal investigating tool used in the studies.

One aspect of this work was the determination of the oxidation states exhibited by these $f$ elements in these matrices, as well as the factors that may control and/or alter these states. With the high-temperature silicate-based glasses, we noted a correlation existed between the oxidation state of the f-elements in the glasses with their high-temperature oxide chemistries. The correlation seems plausible given the silica based network encountered in the glasses, and that the products were formed and maintained in air. One exception to this general correlation was observed with americium, where a trivalent rather than a tetravalent oxidation state was observed.

Oxidation states reported in the literature for americium range from two through seven. Although trivalent americium is frequently encountered in acidic solutions, when americium salts or oxides are calcined in air up to $1200^{\circ} \mathrm{C}$, the oxide formed is nominally americium 
dioxide. In contrast, after heating americium in air in these three silicon-oxygen, glass matrices, only trivalent americium was observed in the products. As trivalent americium was used in preparing the sol-gel glasses and americium dioxide was dissolved in the glasses prepared at high temperature, this required the reduction of americium in two glasses and avoidance of oxidation in the third glass. The lanthanide homolog of americium, europium, both in general and in these three glass matrices, is encountered in its trivalent oxidation state. Thus, americium behaves similarly to europium in the glass products studied but behaves differently from europium in its oxide formation in air. Americium's behavior in the high-temperature glasses mimics the behaviors of all of the lanthanide elements, except for cerium.

Many glass matrices prepared with multi-component f-elements to their maximum solubility limit are not suitable for spectroscopic studies, frequently being opaque and/or very dark (e.g., especially glasses containing cerium, neodymium and plutonium). To aid our spectroscopic studies, our approach was to initiate these studies using a single f-element component (e.g., americium) and at concentrations best suited for spectroscopic analyses (typically 5-20 weight $\%$, depending upon the element). In this studies of americium reported here, both absorption and fluorescence spectral measurements were employed.

Some of the main scientific questions about immobilizing glasses deal with the stability of the materials formed, mobility/diffusion characteristics, and/or the leaching of the f-elements contained in the matrices. The oxidation states of these elements in such hosts is of primary importance in this regard, affecting many of the physicochemical properties of the solid phase, the susceptibility of the material to leaching from the matrix if contacted by aqueous media, and the nature of the species that may be solubilized. There are serious efforts to model the behavior and performance of such isolation matrices, especially given that their performance must be evaluated for time frames which exceed experimental capabilities. The oxidation states of the elements immobilized in such matrices is therefore of critical importance and must be one of the major considerations in modeling and evaluations.

The behavior of americium in the glass hosts described here addresses both its fundamental and technological science. Reported here are the results of studies aimed at examining the oxidation state exhibited by americium in three glass hosts prepared at ambient and elevated temperatures. Potential explanations for the behavior of americium are offered in terms of its basic chemistry and the nature of the americium-oxygen system.

\section{EXPERIMENTAL}

\section{Materials}

The americium $\left(\mathrm{Am}-243 ; \mathrm{t}_{1 / 2}=7.4 \times 10^{3} \mathrm{y}\right)$ employed in these studies was obtained as a product of the High Flux Isotope Reactor located at Oak Ridge National Laboratory and made available through the BES program of DOE. Aqueous solutions of americium (III) in $0.5 \mathrm{M}$ nitric acid were obtained by diluting with water the eluant obtained from a cation ion-exchange column during the purification procedure [1]. Americium dioxide was prepared from this stock solution by precipitating its oxalate salt and calcining it in air at $1000^{\circ} \mathrm{C}$.

Two high-temperature glass formulations were used in these studies. One was a higher melting material $\left(1400^{\circ} \mathrm{C}\right)$ with the following nominal weight percentages: $\mathrm{SiO}_{2}(30 \%) ; \mathrm{B}_{2} \mathrm{O}_{3}$ $(6 \%) ; \mathrm{BaO}(3 \%) ; \mathrm{Al}_{2} \mathrm{O}_{3}(13 \%) ; \mathrm{PbO}(10 \%)$ and f-element oxide (nominally $38 \%$ ). To allow a variation of the americium content while maintaining a constant f-element content, a lanthanum oxide-americium oxide ratio was used in preparing these particular glasses. The components 
without the americium were first melted to form a stock glass: cooled; ground to a fine powder; and the latter then ground with the desired quantity of americium dioxide. This final mixture was then heated in platinum boats to $1450^{\circ} \mathrm{C}$, maintained at this temperature until dissolution was complete (4-8 hours) and then slowly cooled to room temperature. The products were obtained in the form of small, transparent glass "jewels", light pink in color.

The second glass formulation was a lower melting glass $\left(850^{\circ} \mathrm{C}\right)$ with the following nominal weight percentages: $\mathrm{SiO}_{2}(50 \%) ; \mathrm{B}_{2} \mathrm{O}_{3}(18 \%) \mathrm{Na}_{2} \mathrm{O}(24 \%) ; \mathrm{CaO}(3 \%)$ and $\mathrm{AmO}_{2}(5 \%)$. The components without the americium were melted and after cooling to a solid, ground to a fine powder. The americium glasses were then prepared by melting an appropriate quantity of this glass formulation in a platinum container at $900^{\circ} \mathrm{C}$ and then adding the solid americium dioxide to the molten glass. After complete dissolution, the molten material was slowly cooled to room temperature. The final products were similar in appearance to the higher-temperature products described above.

The sol-gel glasses were prepared by mixing $0.1 \mathrm{M}$ Am (III) solutions ( $0.5 \mathrm{M}$ nitric acid) with equal volumes of methanol and tetramethylorthosilicate in small glass cylinders with a restricted top to depress volatilization of the volatile components. After 24-48 hours, clear, solid-glass (pink in color) products were formed, which were removed as a single piece from the cylinders.

\section{Spectroscopy}

Portions of the each glass product were taken and sealed in glass tubes with optically flat sides designed in-house for our spectroscopic measurements. A Jobin Yvon/Instruments SA model Ramanor HG.2S spectrometer (resolution $0.5 \mathrm{~cm}^{-1}$ at $514 \mathrm{~nm}$ ) was employed in conjunction with a microscopic attachment (Nachet, model NS-400). For the absorption studies, a xenon-arc lamp was used and the dispersed light measured via a photon counting system (cooled photomultipler; multichannel analyzer) interfaced with a PC computer using Galactic Industries, "Spectra-Calc" software. Fluorescence measurements were made using many of these components but employing a 5 watt argon laser (at reduced power levels to avoid excessive heating of the samples) as the excitation source.

\section{RESULTS}

\section{Absorption Spectra}

The spectral region of the microscopic instrumentation was limited to $400-850 \mathrm{~nm}$. Due to the irregular shaped specimens of the americium glass, absorption extinction coefficients were not determined. The main purpose of the spectral examinations was to determine qualitatively the oxidation state(s) of the americium in the glasses.

An absorption spectrum obtained from the americium glass prepared by dissolving americium dioxide in the molten host at $1450^{\circ} \mathrm{C}$ is shown in figure $1 \mathrm{~A}$. Absorption spectra for these americium glasses show unequivocally that the americium in the glass posses an oxidation of three. This solid state absorption spectrum matches well with solution spectra reported for Am (III) ions in different solution media [2,3], in the solid state [4] and the free ion energy levels for the $\mathrm{Am}^{3+}$ ion [5]. The major absorption maxima in the absorption spectrum were at 509, 784, and $834 \mathrm{~nm}$ (see Table I), with the main absorption being at $509 \mathrm{~nm}$ (well-established absorption 
for trivalent americium). This peak has a definitive shoulder at a slightly longer wavelength. Absorptions assigned to other oxidation states of americium were not observed.

The americium glass prepared at $1450^{\circ} \mathrm{C}$ also displayed emission peaks when excited by 457.9 $\mathrm{nm}$ radiation (Figure 2). Four emission peaks were observed: a weak emission at $11990 \mathrm{~cm}^{-1}$ or $834 \mathrm{~nm}$; a very strong emission at $14,431 \mathrm{~cm}^{-1}$ or $693 \mathrm{~nm}$; a medium emission at $16587 \mathrm{~cm}^{-1}$ or $603 \mathrm{~nm}^{\prime}$ and another weak emission at $19,153 \mathrm{~cm}^{-1}$ or $522 \mathrm{~nm}$ (see Table I). These emissions are also characteristic of americium having a trivalent oxidation state.

The absorption spectrum obtained from the second glass (lower melting, $850^{\circ} \mathrm{C}$, soda borosilicate) prepared at elevated temperatures is not shown. These products gave nearly identical absorption and emission spectra to those shown in figures $1 \mathrm{a}$ and 2 for the higher melting glass product. The shoulder at about $515-520 \mathrm{~nm}$ was even more pronounced for this product. Again, showing that only trivalent americium was present in the glass.

The two remaining spectra in figure 1 ( $1 \mathrm{~b}$ and $1 \mathrm{c}$ ) were obtained from glasses prepared via a sol-gel technique. The spectrum in figure $1 \mathrm{~b}$ was obtained from the glass following solidification at ambient temperatures, whereas the spectrum in figure 1c was obtained at ambient temperatures after the glass had been heated to $800^{\circ} \mathrm{C}$. Emission spectra obtained from these two products were essentially the same as shown in figure 2 . It was concluded again that both products contained only americium in its plus three oxidation state. The main difference noted between these two spectra was that the spectrum in figure $1 \mathrm{~b}$ was "simpler", essentially having absorptions only at $509 \mathrm{~nm}$ and $834 \mathrm{~nm}$.

The absorption spectrum for the sol-gel glass prepared at ambient temperature ( $1 \mathrm{~b})$ is interesting in that there is only a hint of a shoulder at $515 \mathrm{~nm}$ and a single broad peak at $834 \mathrm{~nm}$. It bears the best resemblance to the solution spectrum reported for dilute perchloric acid solutions of trivalent americium [2], which was reported to have a very sharp absorption (no shoulder) at $505 \mathrm{~nm}$ and a smaller, slightly broadened absorption peak at $810 \mathrm{~nm}$. With greater complexation in aqueous media (e.g., changing to more concentrated nitric acid media) broadening and/or splitting of these two absorption peaks occurs, producing shoulders or peaks at $515 \mathrm{~nm}$ and 780 $\mathrm{nm}$. The spectra for the two high-temperature americium glasses and the sol-gel glass heated to $800^{\circ} \mathrm{C}$ all show these "shoulders". We believe that these changes (broadening /splitting) reflect either or both a "complexation effect" and/or the effect of a stronger crystal field encountered in the glass matrix; crystal fields in the solid matrix may be stronger than fields encountered in aqueous media. A more detailed examination of the absorption and emission spectra, the spectroscopic assignments and interpretations of bonding/crystal field effects will be covered in a subsequent paper. The main conclusion of importance from the absorption and emission spectra in the present paper is that in the three glasses, americium was present only in its trivalent oxidation state.

TABLE I. Absorption Data for the Three Americium Glasses

\begin{tabular}{llc}
\hline Preparation & Absorption maxima, nm & Emission, nm: 457.9 nm excitation \\
& & \\
\hline $\mathrm{AmO}_{2}$ in $1450^{\circ} \mathrm{C}$ glass & 509 major & 833 weak (not shown) \\
and & 520 shoulder & 692 strong \\
$\mathrm{Am}$ (III) in sol-gel $\left(800^{\circ} \mathrm{C}\right)$ & 784 broad, medium & 581 weak + \\
& 834 “" " & 522 weak \\
$\mathrm{Am}(\mathrm{III})$ sol-gel $25^{\circ} \mathrm{C}$ & $505 ;$ sharp; 825 broad & similar to the above
\end{tabular}




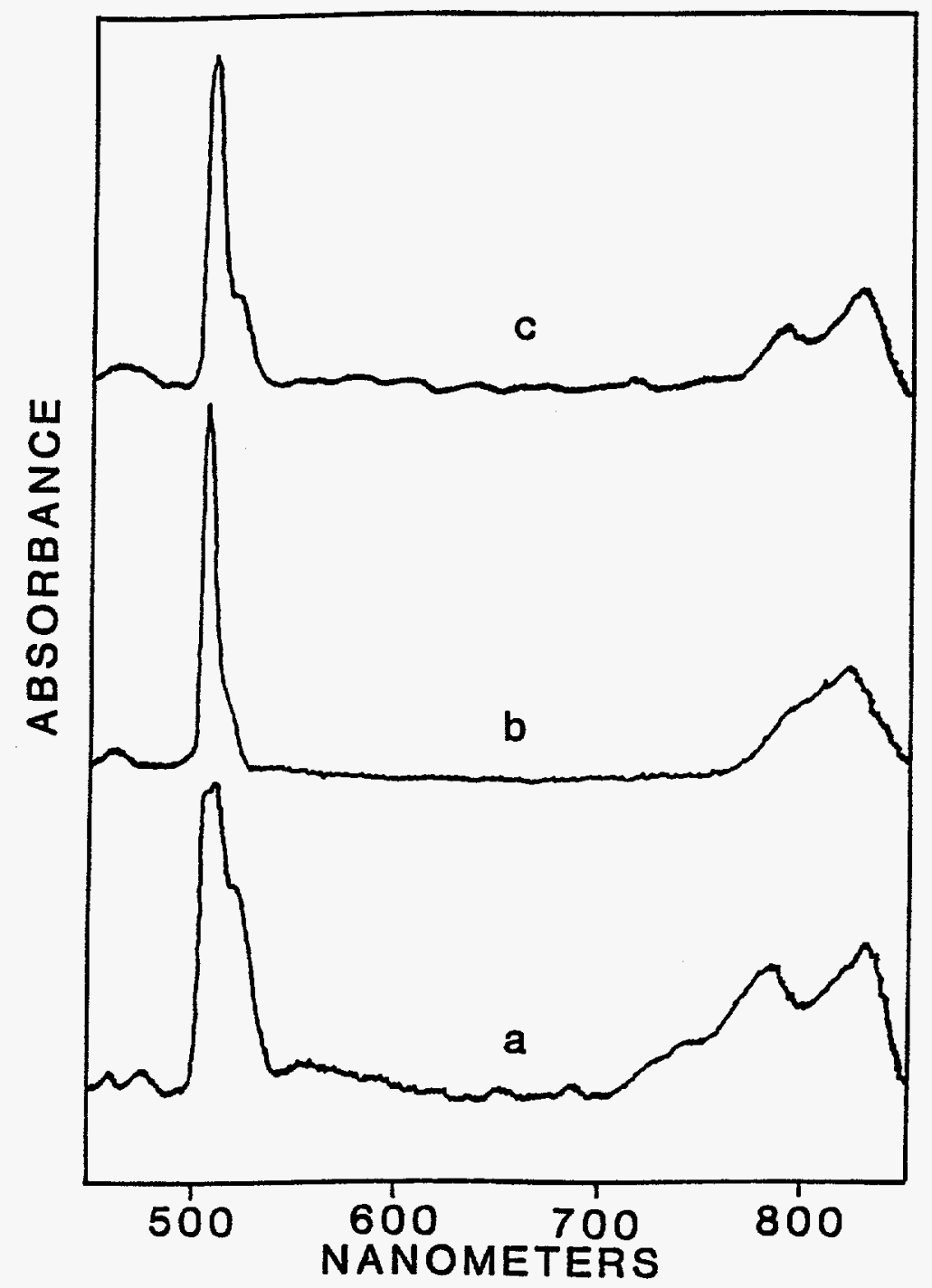

Figure 1: Solid State Absorption Spectra For Am In Glasses; (a) $1450^{\circ} \mathrm{C}$ Glass; (b) Sol-Gel Glass; (c) Sol-Gel Glass After Heating to $800^{\circ} \mathrm{C}$.

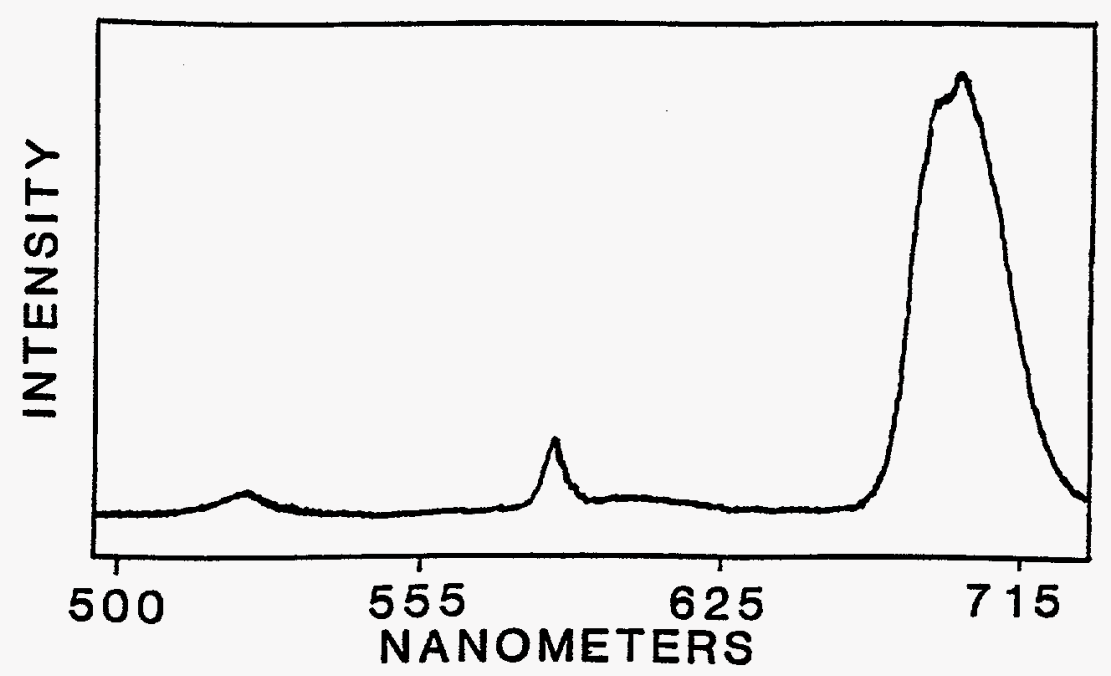

Figure 2: Emission Spectrum From Am in the $1450^{\circ} \mathrm{C}$ Glass; Excitation With $457.9 \mathrm{~nm}$ Radiation. 
Given that the glass matrix consists essentially of a silicon-oxygen network, and that the glasses are prepared/heated in air, it would seem that some correlation should exist between the oxidation states acquired in oxides in air and in the glass products formed in air. Indeed, in our studies of the oxidation states of the $4 \mathrm{f}$ - and $5 \mathrm{f}$-elements acquired in glasses (all the $4 \mathrm{f}$ elements; and the 5 f-elements, $\mathrm{Np}$-Es), it would appear that only americium and uranium deviate in this regard. In such glasses, the oxidation state of americium is plus three and for uranium an oxidation of four, five or six (depending of the oxygen fugacity) based on reports by others [4-7]. The expected oxides at these temperatures should consist of tetravalent americium and uranium. Trivalent and tetravalent ions are generally accepted as being incorporated into the silicate matrices and mono- and divalent ions as network modifiers, but this difference does not provide a rational for the observed behaviors of these two elements. For glasses prepared between 600 and $1000^{\circ} \mathrm{C}$, glasses would be expected to contain tetravalent americium and uranium based on the oxides that are stable at these temperatures in air. As we have not studied uranium glasses, additional discussions here will not include them.

As the first glass we examined was prepared at $1450^{\circ} \mathrm{C}$ with americium dioxide, it was first thought that thermal reduction of the dioxide before or during dissolution in the molten glass may have been responsible for the generation of trivalent americium in the product. The loss of oxygen from americium dioxide is known to occur at elevated temperatures [8]. The concept was that upon solidification, which occurred at sufficiently high temperature (e.g., $1400^{\circ} \mathrm{C}$ ), reoxidation upon subsequent cooling may not have been achieved. However, also obtaining trivalent americium in the glasses prepared at $850^{\circ} \mathrm{C}$ and the retention of trivalent americium in the sol-gel glasses during heating up to $800^{\circ} \mathrm{C}$ in air, both suggested this concept was not correct. In the latter case, it would have been expected that decomposition of residual nitrate at elevated temperatures (e.g., about $600^{\circ} \mathrm{C}$ ) should have promoted formation of tetravalent americium.

Further, microscopic examination of the glass dissolution of americium dioxide at $850^{\circ} \mathrm{C}$ showed that dissolution of the americium dioxide was accompanied by an evolution of gas, believed to be oxygen, as observed when we dissolved the higher oxides of praseodymium and terbium $\left(\operatorname{Pr}_{6} \mathrm{O}_{11}\right.$ and $\left.\mathrm{Tb}_{4} \mathrm{O}_{12}\right)$ in this glass matrix at $850^{\circ} \mathrm{C}$. In the cases of praseodymium and terbium, the glass products also contained only the trivalent oxidation state of these lanthanides.

Several studies have examined cerium glasses. In our preparations and in other studies of cerium glasses, cerium is frequently found in its tetravalent oxidation state, although mixtures of trivalent and tetravalent cerium have also been reported. The equilibria between trivalent and tetravalent states can be shifted by the experimental parameters. One report [9] suggests that the tetravalent state is favored by greater basic nature of the glass, a higher concentration of cerium, and by the oxygen activity in the glass (a function of the glass composition that is difficult to measure quantitatively).

Comparing oxidation couples for the f-elements can serve as an approximate guide for which oxidation state (or multiple states) may be expected for the element when it is placed in a glass host. Although such oxidation couples (or oxygen potentials ) for glass media are not available, some guide in the order of stability of tetravalent states can be obtained by examining general III-IV couples for the f-elements [10]. The latter suggest the following order of stability for the tetravalent oxidation states: $\mathrm{Np}>\mathrm{Pu}>\mathrm{Ce}>\mathrm{Am}>\mathrm{Tb}>\mathrm{Pr}$, where americium has only a slightly lower indicated stability than cerium.

It is known that trivalent americium is generally encountered in acidic solutions and higher oxidation states of americium require complexation or are obtained in alkaline media, where 
stabilization is afforded by anion complexes with oxygen. In the americium-oxygen solid state system, stability is achieved by the fluorite lattice of the dioxide. With the cubic sesquioxide of americium (body center cubic, $\alpha-\mathrm{Mn}_{2} \mathrm{O}_{3}$ structure) care must be exercised to avoid its oxidation by rapid insertion of oxygen into the lattice vacancies to form the dioxide. Thus, a loss of stability afforded by the fluorite lattice (e.g., during dissolution of it into a glass matrix) can alter the stability of americium's tetravalent state in the glass matrix, even though it would seem the silicate's oxygen network should also stabilize the tetravalent state.

When f-element oxides are put into a glass matrix, they may dissolve or be merely dispersed in the glass. When only dispersed, a true homogeneous glass is not formed. The product may not appear transparent and X-ray diffraction analysis can yield weak diffraction patterns. We believe the three types of americium glasses discussed here contained fully dissolved americium. All were transparent under microscopic examination and did not yield any X-ray diffraction pattern. Thus, when the americium dioxide dissolved in the two high temperature glass preparations, the stability of the fluorite lattice was lost, oxygen was evolved, and the resulting trivalent americium was the oxidation state stable in the glass matrix.

In the sol-gel glasses, the trivalent americium was dispersed homogeneously together with residual solvents and anions in a solid silicon-oxygen and/or hydroxyl network. During aging at ambient temperatures, and subsequent step-wise heating up to $800^{\circ} \mathrm{C}$ in air, the trivalent state of americium remained sufficiently stable to be retained in the changing glass matrix and during nitrate decomposition. In separate experiments with plutonium in identical sol-gel preparations [11], trivalent plutonium could be incorporated and maintained into the solidified sol-gel matrix at ambient temperatures. However, the plutonium in these products were sensitive to oxidation and formed tetravalent plutonium. Heating to $100^{\circ} \mathrm{C}$ or above rapidly caused to the trivalent plutonium to be oxidized totally to its tetravalent state. The tetravalent state is also the state exhibited by plutonium in glasses formed at high temperatures in air by dissolving plutonium dioxide in glass matrices. Thus, it is the thermodynamic stability (e.g., pseudo-oxidation potentials or oxygen potentials) of the f-element under the particular conditions which determine the oxidation state(s) that will be exhibited by the f-elements in the different glasses. This state may change when stabilization is afforded by other conditions (e.g., the fluorite lattice in the case of americium).

\section{CONCLUSION}

The goal in this study was to ascertain fundamental information regarding the nature of americium in glasses. One specific question regarded the oxidation state that americium would acquire in the glasses, as it has important implications in modeling considerations, diffusion processes, long-term mobility and the leachibility of americium in such glass hosts. In the work described here, it is clear that trivalent americium was obtained in the glasses prepared by hightemperature dissolution's of americium dioxide. Further, when trivalent americium was incorporated into sol-gel glasses at ambient temperature, and then heated to various temperatures up to $800^{\circ} \mathrm{C}$ in air, there was no evidence to suggest oxidation of the americium and trivalent americium was observed in the resulting products when cooled to $25^{\circ} \mathrm{C}$. This was in contrast to the behavior reported for trivalent plutonium under identical conditions and to the behavior encountered when common salts of trivalent americium are calcined in air. Apparently, the silicon-oxygen network provided by the glasses, even though basic in nature, does not offer sufficient stability for tetravalent americium. 
The retention of a trivalent state for americium reflects the thermodynamic stability of this oxidation state in this particular environment, which can be contemplated by comparing relative pseudo-oxidation states or oxygen potentials of americium and other f-elements. It is very likely that the additional stability afforded by the cubic, fluorite lattice of americium dioxide plays an important role in the formation of tetravalent americium in air atmospheres below $1200^{\circ} \mathrm{C}$. Indeed, americium tetrafluoride decomposes at lower temperatures than does the dioxide, indicating a lower stability of tetravalent americium in this fluoride matrix. Principally, americium is in a pivotal position in the actinide series, where the transplutonium elements are becoming more lanthanide-like and the trivalent oxidation state is becoming the preferred oxidation state.

The results of this study are that americium will acquire a trivalent oxidation state in glass media, for the particular glasses examined and those with similar properties. However, it must be recognized that in other formulations (different basic nature, oxidants, complexants, etc.) and the presence of other elements that may afford redox couples with americium, it may be possible to acquire higher oxidation states, in part or total, for americium.

\section{ACKNOWLEDGMENT}

Research sponsored by the Division of Chemical Sciences, Office of Basic Energy Sciences, US Dept. of Energy, under contract DE-ACO5-960R22464 with Oak Ridge National Laboratory, managed by Lockheed Martin Energy Research Corp.

\section{REFERENCES}

[1] L. J. King, J. E. Bigelow and E. D. Collins, in Transplutonium Elements-Production and Recovery, edited by James D. Navratil and Wallace W. Schulz (ACS, Washington, DC, 1981), pp.133-145; and references therein.

[2] W. W. Schulz, The Chemistry of Americium, ERDA Critical Review Series, Report TID26971 (Technical Information Center, Oak Ridge, TN, 1976), pp. 72-77.

[3] W. W. Schulz and Robert A. Penneman, in The Chemistry of the Actinide Elements, 2nd ed., edited by J. J. Katz, G.T. Seaborg and L. R. Morss (Chapman and Hall, New York, 1986),pp. 926-930.

[4] D. G. Karraker, J. Am. Ceram. Soc., 65, 53 (1982).

[5] W. T. Carnall and H. M. Crosswhite, Report ANL-84-90, USDOE Report , 1985.

[6] I. Poirot, M. Beauvy, M. Boge, D. Bonnisseau, A. Blaise, J. M. Fournier and P. G. Therond, J. Less-Common Metals, 121,656 (1986).

[7] H. D. Schreiber, J. Less-Common Metals, 91,129 (1983).

[8] T. D. Chikalla and L. Eyring, J. Inorg. Nucl. Chem., 29, 2281(1967).

[9] A. Paul and R. W. Douglas, Physics and Chem. of glasses, 6,212 (1965).

[10] R. G. Haire and L. Eyring, in Handbook on the Physics and Chemistry of Rare Earths, Vol. 18, Lanthanides/Actinides: Chemistry, edited by K.A. Gschneidner, Jr., L. Eyring, G. R. Choppin and G. H. Lander, (North-Holland, New York, 1994) pp. 481-482.

[11] N. Stump, R. G. Haire and S. Dai, Proceedings, Dec., 1996, MRS Symposium II. 